\title{
Laparoscopic Cholecystectomy; Complications and Conversion to Open Cholecystectomy
} \author{
Juliàn Novoa $\mathrm{MF}^{3}$ and Idelfonso Esquivel $\mathrm{M}^{3}$ \\ ${ }^{1}$ Hospital Español de la Sociedad de Beneficiencia Española, Mexico \\ ${ }^{2}$ Universidad Popular Autónoma del Estado de Puebla, Mexico \\ ${ }^{3}$ Universidad Autónoma de Guadalajara, Mexico
}

Verdeja Robles $\mathrm{CA}^{1,2 *}$, Turcio Aceves $\mathbf{0}^{1,3}$, Zubia Arellano $\mathrm{CP}^{1}$, Norberto Gonzalez $\mathrm{JJ}^{1}$, Valles Hernandez $\mathrm{AC}^{1}$,

Received: May 05, 2018; Published: June 20, 2018

*Corresponding author: Cesar Alonso Verdeja Robles, Universidad Popular Autónoma del Estado de Puebla, Hospital Español de la Sociedad de Beneficiencia Española, Mexico, Tel: 527442233395; Email: cesaralonso.verdeja@upaep.edu.mx

\begin{abstract}
Laparoscopic cholecystectomy (LC) has become the gold standard treatment for benign gallbladder disease since it was first introduced by Mühe in 1985, followed by Mouret in 1987. The laparoscopic cholecystectomy is defined as the removal of gallbladder through a key-hole-sized incision, this procedure is associated with less postoperative pain and better aesthetic results. The frequency of LC complications varies among $0.5 \%$ to $6 \%$, leading to a new spectrum of intraoperative and postoperative complications, being the iatrogenic perforation of the gallbladder with an incidence of $10-30 \%$ the principal intraoperative complication. With the advent of laparoscopic cholecystectomies, the indications to perform an open cholecystectomy have decreased.

The most common cause (2\% to $10 \%)$ to do an open cholecystectomy is performed is when converting from a laparoscopic to open cholecystectomy. The principal predictors of complications regardless LC or PC are: gallbladder wall thickness $>3 \mathrm{~mm}$, Acute Cholecystitis (AC), obesity, male sex, and instrumentation failure. Nevertheless in Sankpal study which evaluated 220LC and 2200C it shown no significant difference in the incidence of complications between these two types of surgery. When analyzing the literature it can be observed that there is no difference between laparoscopic and open cholecystectomy with respect to complications and indications. However, when performing a laparoscopic cholecystectomy there is always a risk of becoming an open cholecystectomy, even so the laparoscopic cholecystectomy continues to be the gold standard and there are advantages of laparoscopic surgery include in comparison with the open procedure like: reduction in tissue trauma, early ambulation, reduced adhesion formation, early return to work and less medication, which certainly make it the choice for treatment in the present.
\end{abstract}

\section{Introduction}

Laparoscopic cholecystectomy (LC) has become the gold standard treatment for benign gallbladder disease since it was first introduced by Mühe in 1985, followed by Mouret in 1987. This procedure has gradually replaced open surgical treatment to become one of the most common surgical procedure performed worldwide, nevertheless they are still compared in their mortality rates, hospital stay, as well as their incidence of biliary tract injury [1-3].

Laparoscopic cholecystectomy is defined as the removal of gallbladder through a key-hole-sized incision, being the traditional procedure using two $10 \mathrm{~mm}$ ports and two $5 \mathrm{~mm}$ ports, but also it can be done with 3 ports, which is associated with less postoperative pain and better aesthetic results [4]. The advantages of laparoscopic surgery include: reduction in tissue trauma, early ambulation, and reduced adhesion formation, early return to work and less medication [5]. When comparing liver function post laparoscopic and open cholecystectomy (OC) it has been shown that in the first postoperative day, liver enzymes especially serum Aspartate amino-transferase (AST), Alanine amino-transferase (ALT) and Gamma-glutamyl transpeptidase (GGT) which are hepatocellular enzymes are more elevated than in the OC groups, associated with diathermy induced injury and carbon-dioxide pneumoperitoneum which causes a reduction in the blood flow to the liver due to an increase intrabdominal pressure that exceeds the normal portal pressure, nevertheless at 1 week post-intervention, the liver enzymes come back to normal in both groups, only evaluated in non-complicated cholecystectomies, in which the traditional 4 ports LC and traditional OC was made and no biliary tract damage or infection was documented, letting us know, that only in patients with severe liver dysfunction prior surgery, an OC should be suggested [2,5].

\section{Complications in Laparoscopic Cholecystectomy}

The frequency of LC complications varies among $0.5 \%$ to $6 \%$, leading to a new spectrum of intraoperative and postoperative complications, being the iatrogenic perforation 
of the gallbladder with an incidence of $10-30 \%$ the principal intraoperative complication [6]. The most serious complication of LC is the bile duct injury leading to severe morbidity, and it is known to be more common in LC than in OC, being the most common cause an anatomical misinterpretation due to: cephalic traction of the fundus that might compress Calot's triangle, twodimensional view, restricted operative field, lateral traction of Hartmann's pouch making difficult to distinguish between the common bile duct (CBD) and the cystic duct (CD), extensive inflammation, edema at Calot's triangle, anatomic variations of the biliary tree, morbid obesity, and hemorrhage $[3,7]$.

The bile duct injury in LC is evaluated by Strasberg classification:

A. Cystic duct leaks or leakage from small ducts in the liver bed.

B. Occlusion of part of the biliary tree, almost invariably the aberrant right hepatic ducts.

C. Transection without ligation of the aberrant right hepatic duct.

D. Lateral injuries to major bile duct.

E. Low common hepatic duct (CHD) stricture, with the length of the CHD stump of $>2 \mathrm{~cm}$.

a) Proximal CHD stricture - hepatic duct stump $<2 \mathrm{~cm}$.

b) Hilar stricture, no residual CHD, but the hepatic ductal confluence is preserved.

c) Hilar stricture, with involvement of confluence and loss of communication between right and left hepatic duct.

d) Involvement of aberrant right sectorial hepatic duct alone or with concomitant stricture of the CHD [3].

\section{Conversion to an Open Cholecystectomy}

With the advent of laparoscopic cholecystectomies, the indications to perform an open cholecystectomy have decreased. The most common because (2\% to $10 \%)$ to do an open cholecystectomy is performed is when converting from a laparoscopic to open cholecystectomy. The principal predictors of complications regardless LC or PC are: gallbladder wall thickness $>3 \mathrm{~mm}$, Acute Cholecystitis (AC), obesity, male sex, and instrumentation failure. Nevertheless in Sankpal study which evaluated 220 LC and 220 OC it shown no significant difference in the incidence of complications between this two types of surgery [8].

Poor visualization and unclear anatomy are typically the reason to convert. Conversion to open cholecystectomy should not be viewed as a complication or a failure but just the opposite. It is showing good judgment to complete the operation in the safest manner possible [5,9]. One of the main predictor factor of turning a LP to an OP is the presence of $\mathrm{AC}$, related with a gallbladder wall thickness $>3 \mathrm{~mm}$, due to the modification of local anatomy increasing the difficulty of identifying the cystic pedicle and the common bile duct $[10,11]$.

\section{Elements that predict the conversion to open surgery} are:
a) Age over 60 years.
b) Male sex.
c) Weight over $65 \mathrm{~kg}$.
d) AC, history of epigastric surgery.
e) Background of epigastric surgery.
f) High values of glycosylated hemoglobin (between diabetic patients).

g) Little experienced surgeon (Table 1).

Table 1: Factors significantly affecting conversion rates.

\begin{tabular}{|c|c|c|c|}
\hline \multicolumn{2}{|c|}{ Variables } & $\begin{array}{c}\text { Conversion } \\
\text { Rates (\%) }\end{array}$ & \multirow{2}{*}{ P Value } \\
\hline \multirow{2}{*}{ Sex } & Male & 11.2 & \multirow{2}{*}{$>0.0001$} \\
\cline { 2 - 3 } & Female & 3.2 & \\
\hline \multirow{2}{*}{ Abdominal tenderness } & Present & 6.3 & \multirow{2}{*}{0.007} \\
\cline { 2 - 3 } & Abscent & 2.5 & \\
\hline $\begin{array}{c}\text { Previous upper } \\
\text { abdominal operation }\end{array}$ & Present & 7.3 & \multirow{2}{*}{0.037} \\
\cline { 2 - 3 } & Abscent & 4 & \multirow{2}{*}{0.00001} \\
\hline $\begin{array}{c}\text { Gallbladder wall } \\
\text { (ultrasonography) }\end{array}$ & Thickened & 30.8 & \multirow{2}{*}{0.037} \\
\cline { 2 - 3 } & Normal & 4.1 & \\
\hline Age (years) & $>60$ & 7 & \\
\cline { 2 - 3 } & $<60$ & 3.9 & \\
\hline \multirow{2}{*}{ Acute cholecystitis } & Present & 16.7 & \multirow{2}{*}{} \\
\cline { 2 - 3 } & Abscent & 2.8 & \\
\hline
\end{tabular}

\section{Conclusion}

When analyzing the literature it can be observed that there is no difference between laparoscopic and open cholecystectomy with respect to complications and indications. However, when performing a laparoscopic cholecystectomy there is always a risk of becoming an open cholecystectomy, some of the risks already mentioned as: gallbladder wall thickness $>3 \mathrm{~mm}$, Acute Cholecystitis (AC), obesity, male sex, and instrumentation failure. Laparoscopic cholecystectomy continues to be the choice although it should always be taken into account that there is a learning curve and it is highly operator dependent. Even so, there are advantages of laparoscopic surgery include: reduction in tissue trauma, early ambulation, reduced adhesion formation, early return to work and less medication, which certainly make it the choice for treatment in the present.

\section{References}

1. Ece I, Ozturk B, Yilmaz H, Yormaz S, Şahin M (2017) The effect of single incision laparoscopic cholecystectomy on systemic oxidative stress: a prospective clinical trial. Ann Surg Treat Res 92(4): 179-183. 
2. Ahmad N (2011) Routine Testing of Liver Function Before and After Elective Laparoscopic Cholecystectomy: Is It Necessary?. JSLS 15(1): 65-69.

3. Martin D, Uldry E, Demartines N, Halkic N (2016) Bile duct injuries after laparoscopic cholecystectomy: 11-year experience in a tertiary center. Bio Science Trends 10(3): 197-201.

4. Gurusamy K, Vaughan J, Rossi M, Davidson B (2014) Fewer-than-four ports versus four ports for laparoscopic cholecystectomy. Cochrane Database Syst Rev (2): CD007109.

5. Thomas PK, Rajendram CV, Aneesh Raj A, Unnikrishnan G (2017) Comparative Study of Changes In Hepatic Function After Laparoscopic Cholecystectomy And Open Cholecystectomy. IJSR 6(3): 1-3.

6. Radunovic M, Lazovic R, Popovic N, Magdelinic M, Bulajic M, et al. (2016) Complications of Laparoscopic Cholecystectomy: Our Experience from a Retrospective Analysis. Open Access Maced J Med Sci 4(4): 641-646.
7. Diamantis T, Tsigris C, Kiriakopoulos A, Papalambros E, Bramis J, et al. (2005) Bile Duct Injuries Associated with Laparoscopic and Open Cholecystectomy: An 11-Year Experience in One Institute. Surg Today 35(10): 841-845

8. Duca S, Bãlã O, Al Hajjar N, lancu C, Puia I, et al. (2003) Laparoscopic cholecystectomy: incidents and complications. A retrospective analysis of 9542 consecutive laparoscopic operations. HPB 5(3): 152-158.

9. Jones MW, Deppen JG (2018) Gallbladder, Cholecystectomy. In: Stat Pearls [Internet]. Treasure Island (FL): Stat Pearls Publishing, London.

10. Sankpal D (2016) Clinical Study of Complications of Laparoscopic Cholecystectomy and Open Cholecystectomy. Journal of Medical Science And clinical Research 4(11): 13745-134651.

11. Ibrahim S, Hean TK, Ho LS, Ravintharan T, Chye TN, et al. (2006) Risk factors for conversion to open surgery in patients undergoing laparoscopic cholecystectomy. World J Surg 30(9): 1698-1704.

\section{Your next submission with Juniper Publishers} will reach you the below assets

- Quality Editorial service

- Swift Peer Review

- Reprints availability

- E-prints Service

- Manuscript Podcast for convenient understanding

- Global attainment for your research

- Manuscript accessibility in different formats

(Pdf, E-pub, Full Text, Audio)

- Unceasing customer service

Track the below URL for one-step submission https://juniperpublishers.com/online-submission.php 